\title{
ANALYSIS OF THE CARBON CONTENT EFFECT ON THE MICROSTRUCTURE AND THERMAL BEHAVIOR OF COBALT-MATRIX DENTAL ALLOY
}

\author{
Karolina Beer-Lech (1) \\ Department of Mechanical Engineering and Automation, Faculty of Production Engineering, University of Life Sciences in \\ Lublin, 28 Głęboka St, 20-612 Lublin, Poland

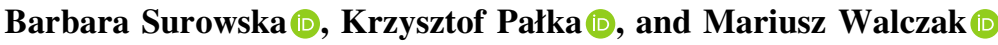 \\ Department of Materials Engineering, Faculty of Mechanical Engineering, Lublin University of Technology, 36 \\ Nadbystrzycka St, 20-618 Lublin, Poland
}

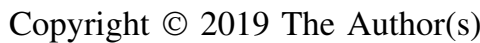

https://doi.org/10.1007/s40962-019-00381-6

\begin{abstract}
The aim of the study was to consider the crystallization interval of dental CoCrMo alloys with different carbon contents as well quantitative and qualitative analysis of changes in their microstructure. The two different batches of Wironit extra-hard alloy (0.413 and 0.806\% C by mass.) were tested. The chemical composition has been carried out as well as microstructure characterization (optical, scanning electron microscopy and X-ray diffraction). A quantitative and qualitative image analysis was performed. The process of differential thermal analysis was carried out in the Balzers VSG-02 vacuum induction furnace. The presence of the Co- $\beta$ solution matrix and $M_{23} C_{6}$ carbides

precipitates dominate. The results showed that the carbon content influences the crystallization parameters of the alloy (in particular increasing the $T_{\text {liq }}$ and decreasing the $T_{\text {sol }}$ with lower carbon content). It was shown that the melting point of the alloy was higher than indicated by the manufacturer (1533-1578 K). For this study, the range of $1635-1660 \mathrm{~K}$ was obtained. This occurrence is very disadvantageous. Using the recommended pouring temperature of $1693 \mathrm{~K}$ for casting the material, which usually has a carbon content of about $0.4 \%$, a low degree of superheat is obtained, which significantly limits or even excludes the castability of the alloy.
\end{abstract} was demonstrated as well as $\mathrm{Co}-\alpha$ solution. Along with the change in the content of carbon in the castings, a qualitative change in the microstructure was noted. Low carbon castings are dominated by blocky eutectic-type precipitates, whereas in high carbon castings, blocky dense
Keywords: dental cobalt alloy, carbon content, microstructure, differential thermal analysis, SEM, $X R D$

\section{Introduction}

Despite the emergence of scientific reports on the harmful effects of some metals on living organisms, metal biomaterials, including casting alloys, are still successfully used in dental prosthetics and maxillofacial surgery. It is caused by a lack of non-metal replacement materials with similar good mechanical and technological properties that also meet the required economic criteria. ${ }^{1}$

Casting cobalt alloys are superalloys used in both medicine and industry. Due to high tensile strength and excellent resistance for creep and high temperature corrosion they are used as elements of aircraft engines and turbines. In recent years, due to high strength, high wear resistance, high thermal conductivity and lower coefficient of friction, aluminum-based composites have also become popular in the aviation and automotive industries. ${ }^{2-6}$ Cobalt alloys as biomaterials, including dental ones, are characterized by very good resistance to pitting and crevice corrosion as well as good mechanical properties. ${ }^{7}$ Requirements for metal materials used in prosthetic restorations are specified in ISO 22674: $2016 .^{8}$

The main components of cobalt alloys used in medicine are chromium, molybdenum, nickel and tungsten. In the cobalt alloys, carbon (considered being an element increasing the stability of the Co- $\beta$-solution) and carbide alloying 
additives are usually present. In works concerning the microstructure of casting alloys, it is usually assumed that the matrix of the alloy is a metastable $\beta$-solution and the proportion of Co- $\alpha$ solution does not exceed several percent and is not the subject of research. ${ }^{9-12}$ The diffraction phase analysis is carried out on isolated precipitates ${ }^{12}$ or on the samples for which the description of the matrix is omitted in the diffraction pattern and the studies are focused on the precipitates. ${ }^{13-16}$ More attention is focused on the $\beta$ into $\alpha$ phase transformation in plastically deformed alloys and those that are produced in the sintering process. ${ }^{17-20}$

Chromium and molybdenum are strong carbide forming elements-forming primary and secondary carbides in $\mathrm{Co}-$ $\mathrm{Cr}-\mathrm{Mo}-\mathrm{C}$ alloys. In the process of crystallization, the $\mathrm{M}_{23} \mathrm{C}_{6}$ chromium-rich primary carbides are formed. $\mathrm{M}_{23} \mathrm{C}_{6}$ carbides, in a specified range of chemical composition and temperature, may occur in equilibrium with $\mathrm{M}_{6} \mathrm{C}$ carbides.

Properties of dental prosthesis and their design have a significant impact on their durability in a complex state of bio-mechanical loads that occur in the mouth during the chewing process. The mechanical loads are responsible in main part for the damages and failures of prosthetic supplies. Clamping forces depending on the size, intensity, duration and location cause varying degrees of stress concentration in the hard tissues of the tooth and dental restorations, which often results in damage to fasteners or damage to the entire denture prosthesis. ${ }^{21}$ The main casting defects that reduce mechanical strength of dental alloys are shrinkage porosity and segregation of chemical composition. The mechanical properties of dental castings are also adversely affected by the tendency to build a coarse crystalline structure and a considerable number of precipitates in interdendritic spaces (carbides or brittle intermetallic phases) that cause the brittleness of alloys. ${ }^{16,22}$ The carbides causing the brittleness of alloys are the continuous carbides at the boundaries of crystallites as well as lamellar carbides. $^{23,24}$

The chemical composition of $\mathrm{Co}-\mathrm{Cr}-\mathrm{Mo}$ biomedical alloys as well as the presence and quantity of the phases and precipitates determines the mechanical and corrosive properties. That is why in the literature studies of morphology, type of precipitates in biomedical cobalt alloys are an important topic ${ }^{23-26}$ and remain valid. ${ }^{22,27-31}$

The subject of study was the commercial dental cobaltbased alloy. The Wironit extra hard is often used in Poland. The ISO 22674:2016 standard ${ }^{8}$ allows alloy manufacturers to specify the percentage of only those elements whose content in the alloy exceeds $1 \%$. The producer of each alloy always joins to them an instruction for use which comprises information about the manufacturing conditions and related properties of the casts. The alloy manufacturer indicates that the percentage of carbon should not be higher than $1 \%$. The research problem is the fact that batches with different percentages of carbon occur within the same grade of alloy. The aim of the conducted study was to consider the differences in the crystallization process of Co-Cr-Mo alloys with different carbon content as well as quantitative and qualitative analysis of changes in their microstructure. Prosthetic practice to assess the temperature from which alloys are cast is very difficult. However, some works showed that the temperature of liquid alloys influences functional properties of the casts and finally the quality of the dentures. ${ }^{32}$ Incorrect selection of casting parameters may result in products with defects or completely exclude the castability of the alloy. The casting parameters also affect the casting microstructure which determines the operational properties (mechanical, corrosive) of the prosthetic elements.

The differential thermal analysis (DTA) of castings with different percentage of carbon content, as well as verification of phase composition and morphology of the precipitates analyses, will allow to determine the characteristic points of solidification of the alloy and the interrelation between changes in chemical composition, and microstructure. A thorough knowledge of the course of the alloy crystallization process will allow obtaining better quality of dental castings.

\section{Materials and Methods}

\section{Material}

The Wironit extra-hard alloy was purchased for the tests. Its chemical composition was tested before and after casting (DTA). Two kinds of batches of Wironit extra hard were selected: $(0.4 \% \mathrm{C}$ - the percentage of carbon most frequently found in this alloy and $0.8 \% \mathrm{C}$-extremely high carbon content found in this alloy).

Using the batches labeled as LCC (low carbon content: $0.413 \% \mathrm{C}$ by mass) and HCC (high carbon content: $0.806 \% \mathrm{C}$ by mass), the castings for DTA were made. After casting in a vacuum and a protected atmosphere (argon), the differences in chemical composition between the input material and castings were statistically insignificant. The chemical composition of the alloy declared by the manufacturer and measured is specified in Table $1 .{ }^{33}$

\section{Chemical Composition Analysis}

In order to investigate the chemical composition of the castings, the Q4 Tasman 130 emission spark spectrometer from Bruker (Germany) was used. The spectrometer was subjected to the standardization procedure on 3 calibration standards: RCo 11/2, RCo14/104 and RCo16/19. The research was carried out on the Co100 research channel. Statistical analysis of the results was made using Dell 
Statistica (data analysis software system), version 13 software by Dell Inc. (2016) company.

\section{Differential Thermal Analysis (DTA)}

The method of thermal analysis of solidifying and cooling metals (differential thermal analysis-DTA) is a known method for determining phase transition temperatures. These temperatures are determined by a continuous cooling process. The changes during crystallization and in solid state are illustrated on the $T=f(t)$ graph in the form of kinks, bends and stops. When the energy extracted or absorbed is small, it is difficult to determine some characteristic temperatures from the $T=f(t)$ graph. In this case, additional and more detailed information is provided by the graph $T^{\prime}=\mathrm{d} T / \mathrm{d} t$, i.e., the speed of temperature change in the analyzed system..$^{34-36}$ In the differential chart, even small changes in the intensity of the heat generated or absorbed cause visible refractions and changes in the direction of the derivative. The crystallization curve determines many characteristic points. The most characteristic are the intersection points with the zero axis. These points, referenced to the cooling curve, determine the characteristic temperatures for stable and equilibrium transformations.

Table 1. The Average Chemical Composition of Batch Materials

\begin{tabular}{|c|c|c|c|c|c|c|c|c|}
\hline Sample's labeling & $\begin{array}{l}\text { Chemical composition } \\
\text { of the castings }\end{array}$ & Co & $\mathrm{Cr}$ & Mo & C & Si & $\mathrm{Mn}$ & Other $\Sigma$ \\
\hline \multirow[t]{2}{*}{ LCC } & $\%$ mass & 63.49 & 28.97 & 4.902 & 0.413 & 0.976 & 0.823 & 0.426 \\
\hline & SD & 0.715 & 0.929 & 0.110 & 0.016 & 0.048 & 0.037 & - \\
\hline \multirow[t]{2}{*}{$\mathrm{HCC}$} & $\%$ mass & 62.91 & 29.44 & 4.562 & 0.806 & 0.980 & 0.951 & 0.351 \\
\hline & SD & 0.227 & 0.520 & 0.171 & 0.056 & 0.028 & 0.016 & - \\
\hline $\begin{array}{l}\text { Chemical composition of the alloy } \\
\text { declared by the manufacturer }\end{array}$ & Average $\%$ mass & 63.0 & 30.0 & 5.0 & $<1$ & 1.1 & $<1$ & $\begin{array}{l}\text { Not } \\
\text { specified }\end{array}$ \\
\hline
\end{tabular}

Bold contains differences in the percentage of carbon
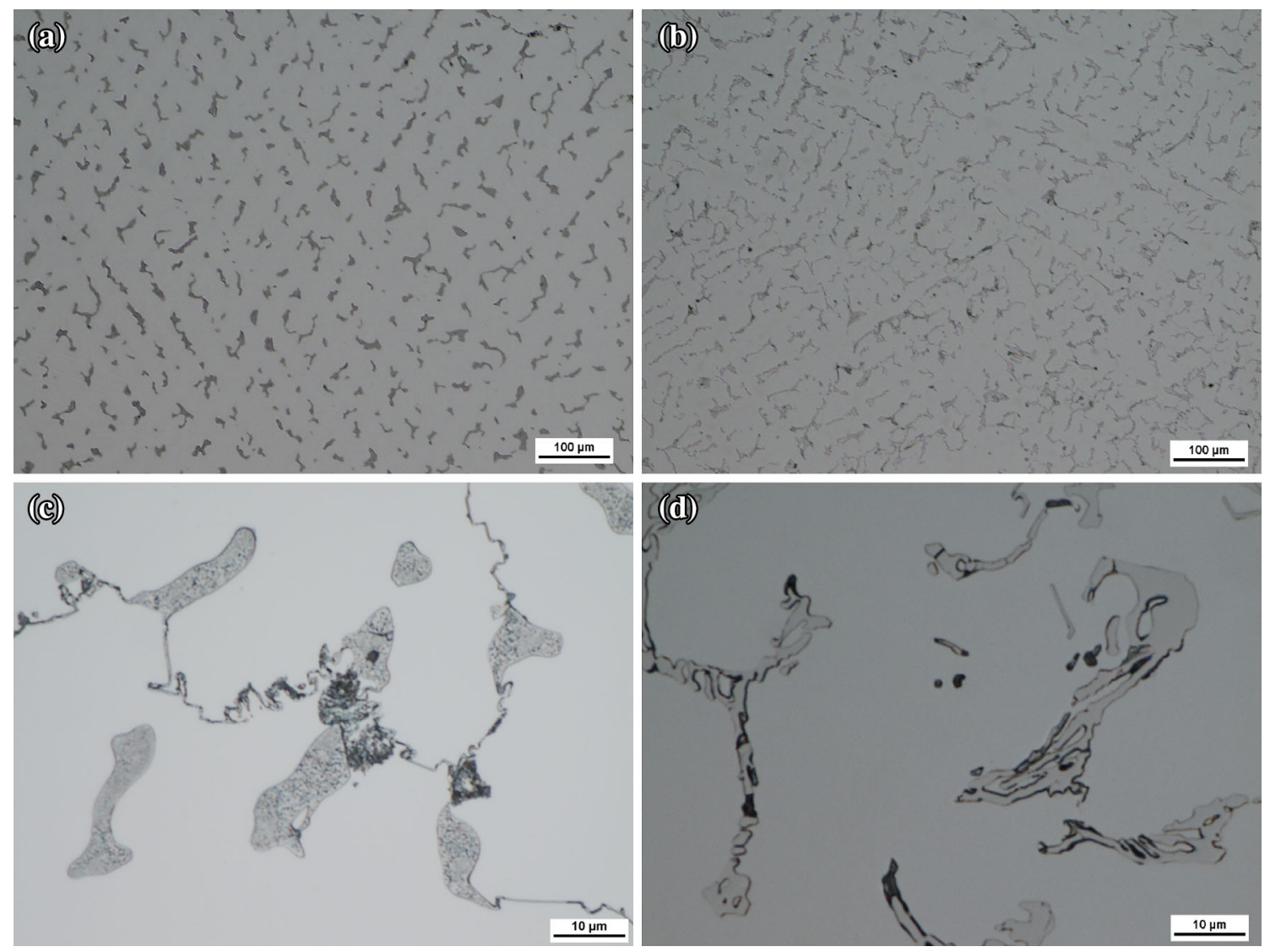

Figure 1. Microstructures of castings: LCC samples: (a, c); HCC samples: (b, d). 

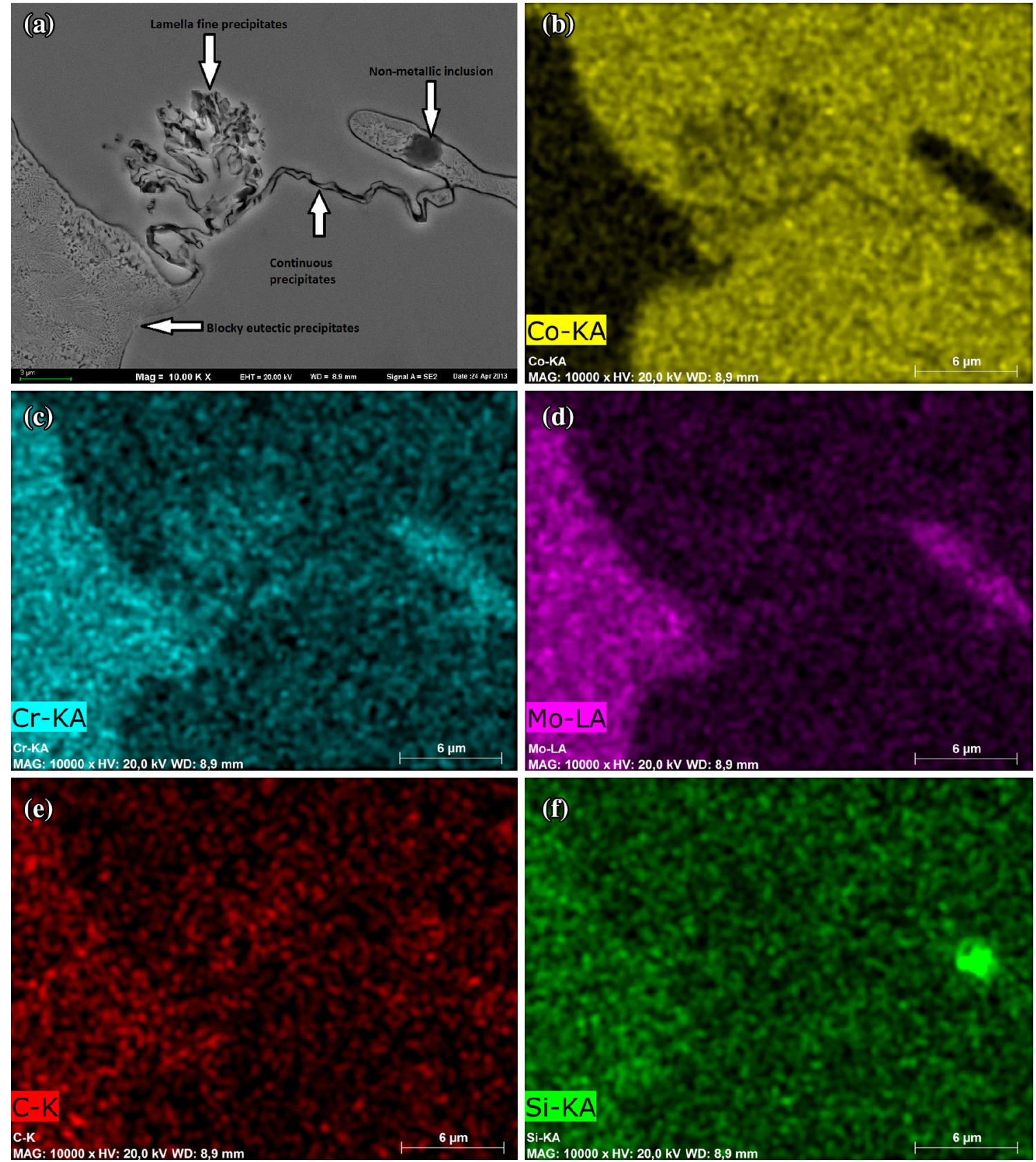

Figure 2. A representative image of precipitates (LCC sample; SEM).

Selected material $(0.4 \% \mathrm{C}$ and $0.8 \% \mathrm{C}$, respectively) was melted in the Balzers VSG-02 vacuum induction furnace using the ceramic crucible $\left(\mathrm{Al}_{2} \mathrm{O}_{3}\right)$. Weight charge was $0.5 \mathrm{~kg}$. The ceramic molds based on $\mathrm{Al}_{2} \mathrm{O}_{3}$ with dimensions: : $\phi=35 \mathrm{~mm} / \mathrm{h}=60 \mathrm{~mm}$ were prepared for DTA analysis. In the thermal center of the mold, a Pt-PtRh10 thermocouple (in a quartz casing) was loaded. The molds were placed in the furnace in which the charge was melted; the molds were poured under an argon atmosphere at a pressure of $\sim 900 \mathrm{hPa}$, the pouring temperature was 1743 K. Solidification was recorded by Crystaldigraph PC$8 \mathrm{~T}$ equipment. Ingots after DTA analysis and after breaking the molds and cooling in air to ambient temperature were cut into the disks (for chemical composition tests and microstructure observations).

\section{Microstructural Analysis}

Samples were included in the acrylic resin (VariDur10 from Buehler $\mathrm{GmbH}$ ). Then, they were grinded on diamond disks corresponding to sanding grains with a grain size of 220-1200 on rotary grinders and polished mechanically using suspensions based on $\mathrm{SiO}_{2}$, on Buehler disks-allowing to obtain a surface roughness of 6,3 and $1 \mu \mathrm{m}$ successively. Samples were digested with royal water. The prepared samples were cleaned in an ultrasonic cleaner in 

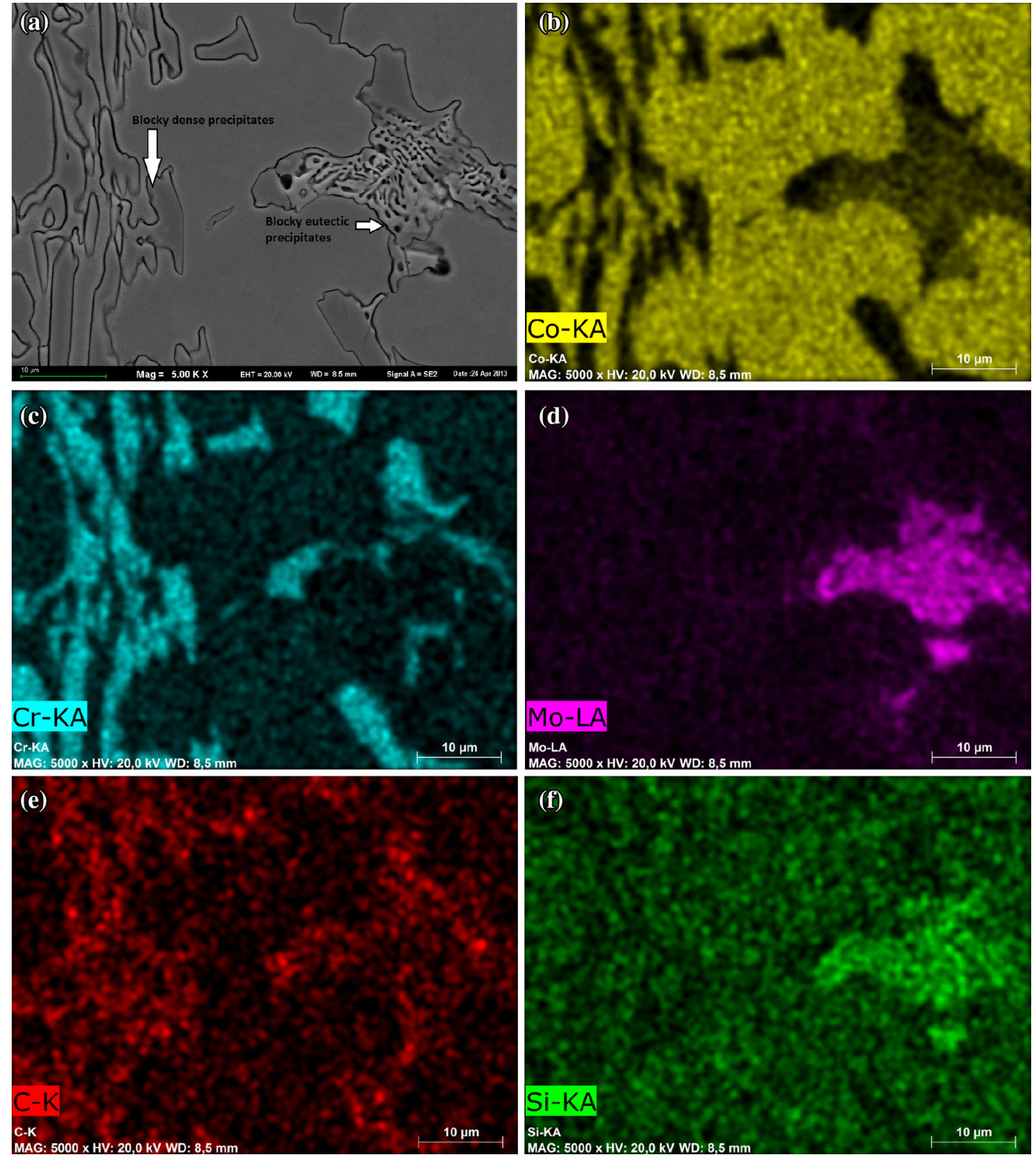

Figure 3. A representative image of precipitates (HCC sample; SEM).

ethyl alcohol and dried with compressed air. The microstructure of the samples after DTA was observed using the Nikon MA200 optical microscope as well as the Carl Zeiss Ultra Plus scanning electron microscope (SEM) with the Bruker EDS microanalyzer. A quantitative image analysis was also performed to determine the percentage of carbide precipitations in the alloys with different carbon content. This analysis was carried out using ImagePro Plus software from the Media Cybernetics (USA).

The X-ray phase analysis was carried out on a TUR M62 $\mathrm{X}$-ray diffractometer (Bragg-Brentano geometry).
The measurement was carried out in the angular range $2 \theta=20^{\circ}-85^{\circ}$ with a $0.01^{\circ}$ step. Pulse measurement time was $3 \mathrm{~s}$ in each angular position.

\section{Results and Discussion}

\section{Microstructural Analyses of Castings}

The alloy is characterized by a coarse crystalline microstructure. The precipitates distributed in the interdendritic spaces are visible on the background of the bright matrix, as well on the borders of the crystallites (Figure 1). 
The ordering of the distribution of precipitates in the crystallite areas was observed for all tested samples.

LCC samples are characterized by dendritic structure and the occurrence of numerous small blocky-type precipitates present in inter dendritic spaces (Figure 1a, d). In addition, on the boundaries of crystallites, the presence of continuous precipitates arranging sometimes in fine lamellas structure precipitates is observed (Figures 1a, c and 2). The complex structure of blocky precipitates (in LCC samples), is developed at higher magnification (SEM). These precipitates have an eutectic character (Figure 2a).

For samples with a higher content of carbon (HCC), the coarsening of precipitates was observed, as well as its significant extension (Figures 1b, d and 3). The blocky precipitations, in these samples, have a dual type structure-the dense and eutectic(Figure 3a).

Image analysis performed using ImagePro Plus software showed differences in the amount of observed precipitates. A larger percentage of precipitates were noted for samples with higher carbon content. Correspondingly, $11.3 \%$ for LCC samples and $13.34 \%$ for HCC samples (Figure 4). A similar tendency was seen by Ramirez and et al. ${ }^{11}$ The authors observed the effect of the percentage of carbon in F75 type alloys $(0.25-0.45 \% \mathrm{C})$ on the number of blocky type precipitates. According to them, the number of blocky type precipitates increases proportionally with the increase of the carbon content.

Quality changes in the microstructure were also noted (Figure 4). The LCC samples were dominated by blocky eutectic precipitates (about 87\%), continuous and lamellar precipitates (jointly) constituted about 13\%. In the HCC samples, the dominance of blocky dense precipitates was observed (about 84\%). Eutectic precipitates constituted only $4 \%$ of all identified precipitates. Continuous

The efect the of amout of carbon on the percentage of precipitates Average value

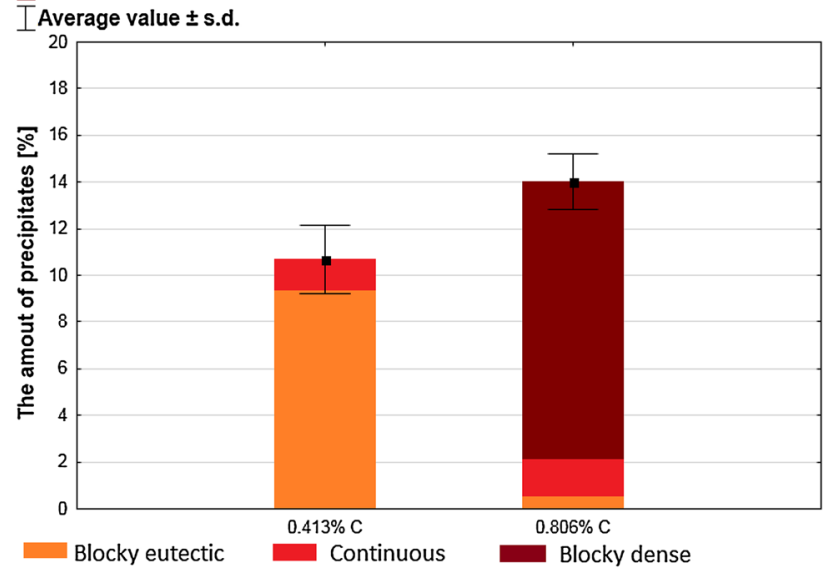

Figure 4. The effect of the amount of carbon on the percentage of precipitates in castings. precipitates accounted for approximately $12 \%$. No lamella fine precipitates were observed in the HCC samples.

In order to identify the precipitates, qualitative studies of the distribution of elements (mapping) were performed in selected characteristic areas of the samples by the EDS method (Figures 2 and 3) as well as phase analysis by $\mathrm{X}$-ray diffraction (Figure 5).

In blocky type precipitates, visible segregation of molybdenum and chromium is observed (Figures $2 \mathrm{c}, \mathrm{d}$ and $3 \mathrm{c}, \mathrm{d}$ ), which in combination with the presence of carbon (Figures $2 \mathrm{e}$ and $3 \mathrm{e}$ ) suggests that these precipitates are carbides-which is confirmed by phase analyses using the X-ray diffraction (Figure 5). In continuous solid type precipitates, chromium is dominant, while carbon and cobalt are also present (Figure $2 \mathrm{a}-\mathrm{c}$, e). Similar segregations and nucleating at blocky-shaped continuous precipitates (in lamella form) were also described in work. ${ }^{13}$

The authors identified them as primary cellular precipitates $\left(\mathrm{M}_{23} \mathrm{C}_{6}+\beta\right.$ phase $)$. The presence of non-metallic inclusions rich in silicon, visible in Figure $2 \mathrm{f}$, also occurred.

The XRD phase composition analysis (Figure 5), for all tested samples, showed that the alloy consists of $\beta$ cobalt solution matrix as well as precipitations in the form of $\mathrm{Cr}_{23} \mathrm{C}_{6}$ carbide. It is not possible to distinguish the peaks from these two phases, so an EBSD analysis was carried out obtaining in the grain areas the fcc phase- $\mathrm{Co}-\mathrm{Cr}-\mathrm{Mo}$ solution and in precipitates areas - the cubic phase-corresponding to $\mathrm{Cr}_{23} \mathrm{C}_{6}$ carbide (in both $\mathrm{LCC}$ and $\mathrm{HCC}$ samples) (Figure 6). These results are partly consistent with the $\mathrm{Co}-\mathrm{C}-\mathrm{Cr}+5 \%$ Mo equilibrium system, ${ }^{37}$ from which it appears that at $1483 \mathrm{~K}$ the alloy with a carbon content up to $0.45 \%$ and sum $\mathrm{Cr}+\mathrm{Mo}$ approx. $35 \%$ should be single-phase with a $\beta$-solution structure. The alloy with carbon content higher than $0.45 \%$ contains in addition to the $\beta$-solution also precipitates of $\mathrm{M}_{23} \mathrm{C}_{6}$

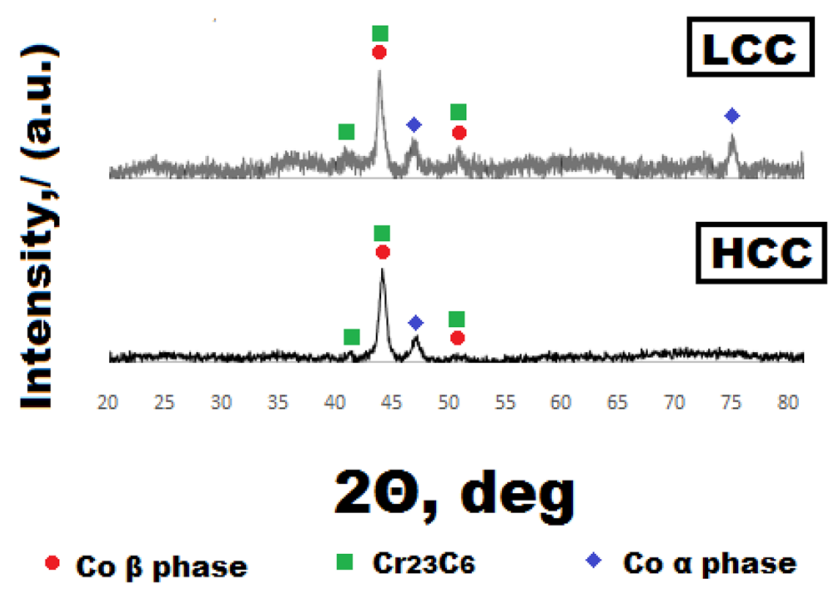

Figure 5. Results of phase analyses of investigated alloys. 


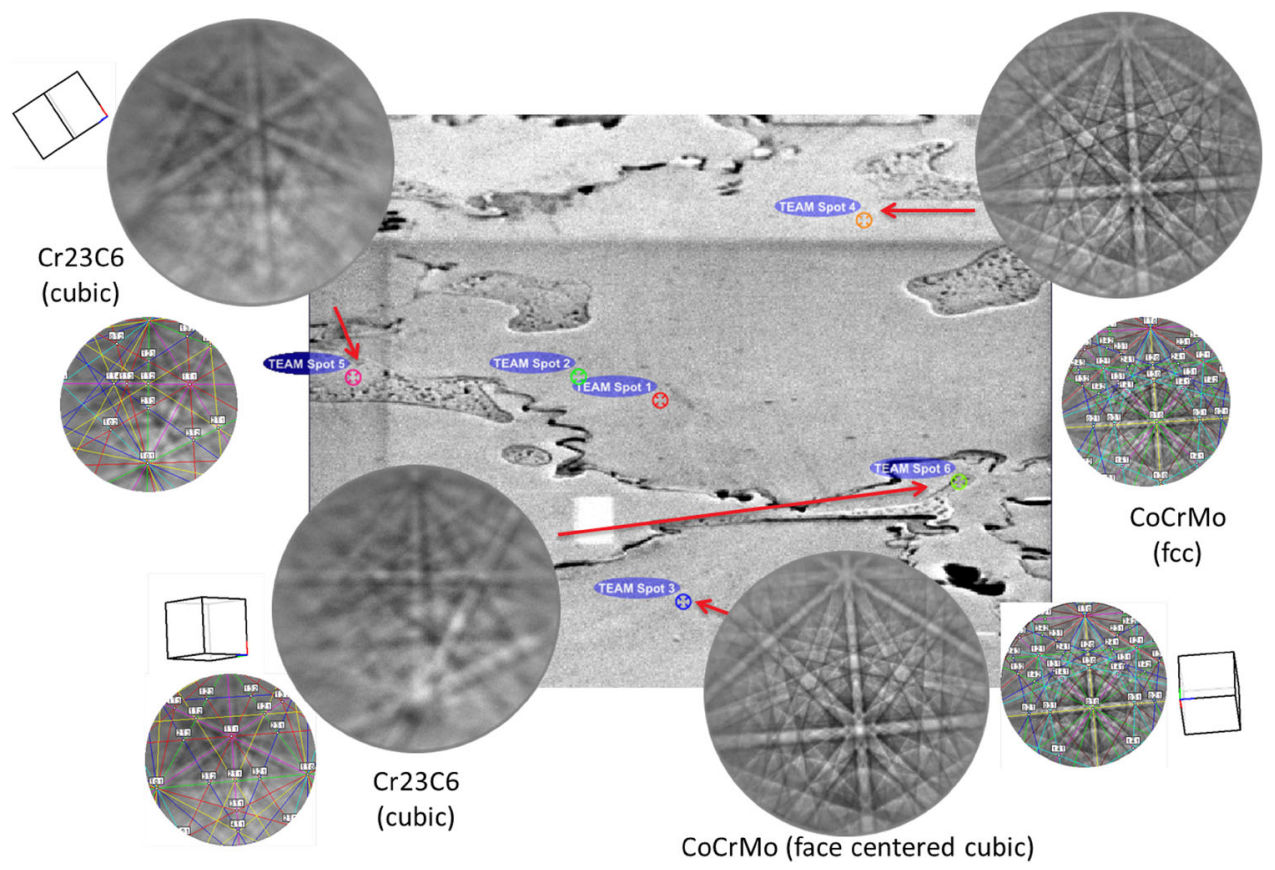

Figure 6. A representative image of EBSD analysis (LCC sample).

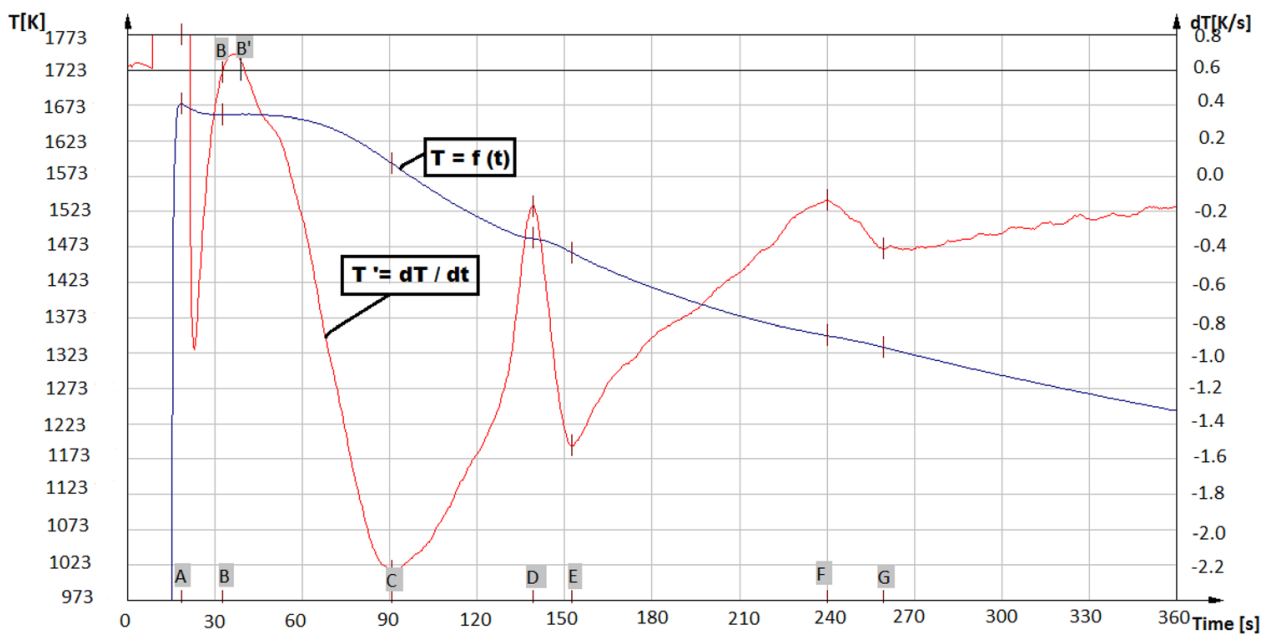

Figure 7. A representative graph of DTA analysis for LCC samples.

carbides. In the majority of investigations of actual $\mathrm{Co}-\mathrm{Cr}-$ Mo-C alloys, carbides or carbides and intermetallic phases are present in the $\beta$-matrix solution. According to the studies by Gomez and co-authors ${ }^{23}$ and Mancha and coauthors, ${ }^{15}$ the primary structure of foundry cobalt alloys (whose chemical composition is similar to the LCC tested samples) immediately after crystallization, consists of a coarsely crystalline matrix of $\beta$ solution and carbidesmainly $\mathrm{M}_{23} \mathrm{C}_{6}$. On the obtained diffraction patterns, peaks were also observed, the identification of which is not unambiguous.

The analysis of the PDF-4 database shows that additional peaks (for LCC, HCC samples) with the 2 theta angle equal to: 46.9 for LCC and HCC samples as well as about 75 , respectively, for LCC samples can come from the $\sigma$ phase or the $\alpha$ phase. The $\sigma$ phase is very often identified by researchers-in Vitallium-type alloys-but with lower carbon content (about $0.25-0.35 \%$ ) [quoting]. ${ }^{11,12,28,38}$ However, taking into account the fact that on EDS images large amounts of cobalt were not observed, in the area of precipitations ( $\sigma$ phase should be created by cobalt and chromium), it is more likely that the tested castings additionally contain the $\alpha$ solution (about 9\% according to the PDF no. : 04-017-1160) constituting the melt matrix together with the $\beta$ solution. This claim is in line with the Mantrala study and coauthors investigating Stellite-21 alloy samples. Peaks 


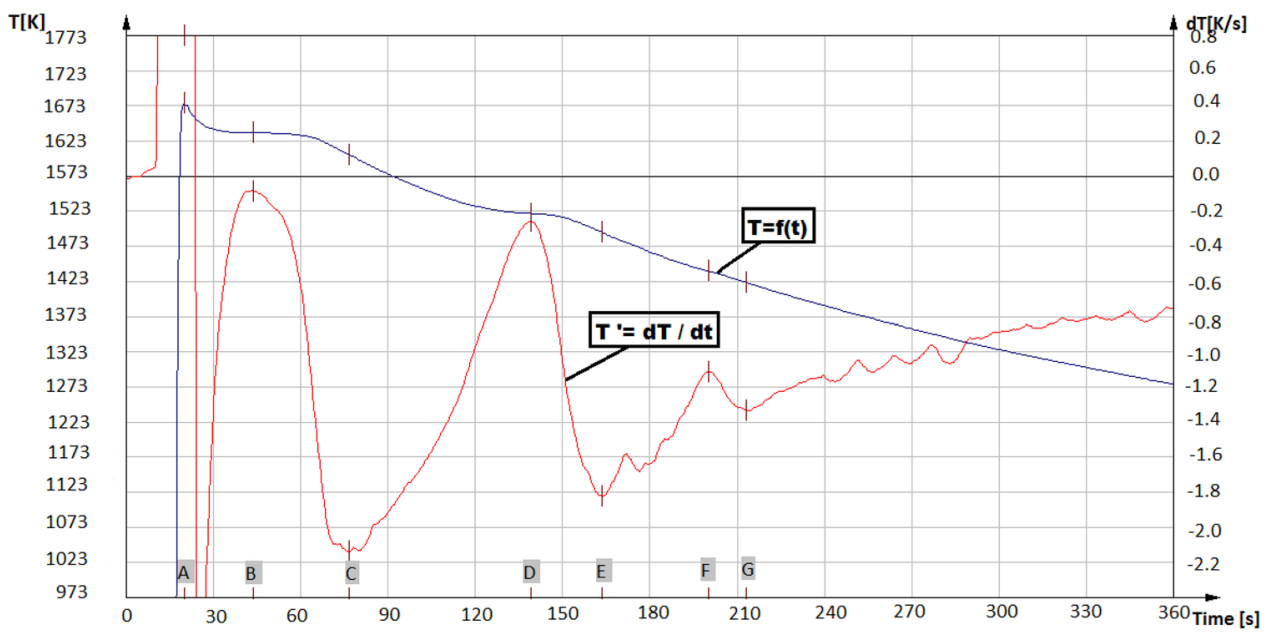

Figure 8. A representative graph of DTA analysis for HCC samples.

Table 2. Thermodynamic Changes of Alloys (from DTA Curves)

\begin{tabular}{lllll}
\hline Content of C (\%) & $T_{\text {lik }}(\mathrm{K})$ & $T_{\text {eut }}(\mathrm{K})$ & $T_{\text {sol }}(\mathrm{K})$ & $T_{\text {eut }}-T_{\text {sol }}(\mathrm{K})$ \\
\hline $0.413(\mathrm{LCC})$ & 1660 & 1485 & 1465 & 20 \\
$0.806(\mathrm{HCC})$ & 1635 & 1520 & 1493 & 27 \\
\hline
\end{tabular}

obtained from diffractometric studies with a very similar value of the $2 \theta$ angle, define as a cobalt solution with Miller indexes (101), which unequivocally suggests the presence of the $\alpha$ solution. $^{39}$

\section{The DTA Results}

From the DTA charts characteristic points describing thermal phenomena occurring during the crystallization of the alloy, defining temperature and time values were determined. Figures 7 and 8 show the cooling and crystallization curves for melts with a carbon content of $0.41 \%$, and $0.81 \%$, respectively, with values of the most important characteristic points (Table 2).

The DTA plots (Figures 7 and 8) show that the carbon content of the batch affects the crystallization parameters, in particular increasing the $T_{\mathrm{liq}}$ and decreasing the $T_{\mathrm{sol}}$ with lower carbon content. Table 3 presents the characteristic points and ranges of transformations with the schematic description. The increase in liquidus temperature is notably for alloys with carbon content below $1 \%$. The melting point of the Wironit extra-hard alloy, according to the manufacturer's specifications, should be in the range of $1533-1578 \mathrm{~K}^{33}$ For this study, the range of 1635-1660 K was obtained (Table 2).This occurrence is very disadvantageous. Using the recommended pouring temperature of

Table 3. Interpretation of DTA Curves of Alloys with Different Carbon Content

\begin{tabular}{|c|c|c|c|}
\hline $\begin{array}{l}\text { Point } \\
\text { tag }\end{array}$ & Temperature & Description & Point determination method \\
\hline B & $\begin{array}{l}T_{\text {lik }}(\max . \\
\text { supercooling })\end{array}$ & $\begin{array}{l}\text { Growth of } \beta \text {-solution crystals_reaching the critical } \\
\text { size of nucleus }\end{array}$ & The first derivative is zero \\
\hline $\mathrm{B}=\mathrm{B}^{\prime}$ & $T_{\text {lik }}$ & Growth of $\beta$-solution crystals-in the $0.81 \% \mathrm{C}$ alloy & The first derivative reaches maximum value \\
\hline $\mathrm{B}^{\prime}$ & $\begin{array}{l}T_{\text {lik } r} \\
\text { (equilibrium) }\end{array}$ & Stabilized growth of $\beta$ solution & The first derivative is zero again \\
\hline $\begin{array}{c}\mathrm{B}^{\prime}-\mathrm{C}- \\
\mathrm{D}\end{array}$ & & Further increase of the $\beta$-solution & Falling of cooling curve \\
\hline $\mathrm{D}$ & $T_{\text {eut }}$ & $\begin{array}{l}\text { Growth of carbide nucleus and other eutectic } \\
\text { phases and increase of eutectics (transient) }\end{array}$ & $\begin{array}{l}\text { Another maximum on the crystallization curve } \\
\text { (the derivative does not reach zero) }\end{array}$ \\
\hline $\mathrm{E}$ & $T_{\text {sol }}$ & $\begin{array}{l}\text { The end of eutectic crystallization-the end of } \\
\text { crystallization of the alloy. }\end{array}$ & Another minimum of the first derivative \\
\hline$F$ & $T_{\mathrm{c}}$ & $\begin{array}{l}\text { Solid state carbide precipitation (type } \mathrm{M}_{23} \mathrm{C}_{6} \text { or } \\
\mathrm{M}_{6} \mathrm{C} \text { ) }\end{array}$ & Another maximum on the crystallization curve \\
\hline G & & The end of phases precipitation in the solid state & Another minimum of the first derivative \\
\hline
\end{tabular}


$1693 \mathrm{~K}$ for casting the material, which usually has a carbon content of about $0.4 \%$, a low degree of superheat is obtained, which significantly limits or even excludes the castability of the alloy. This is also important in the case of casting a small amount of alloy, without chemical composition checking - as is the case in dentistry. Analyzing the form of cooling and crystallization curves of the castings, it can be concluded that the final stage of crystallization, described as an eutectic transformation, occurs in a transient fashion in the $\mathrm{T}_{\text {eut }}-T_{\text {sol }}$ temperature range (the first derivative does not reach zero). This shape of the cooling curve (before complete crystallization (solidus) is observed in the DTA method for multicomponent alloys, in the non-equilibrium process with the formation of lowmelting multi-phase eutectics. ${ }^{34}$

\section{Conclusions}

The tests showed a very strong relationship between the carbon content and the microstructure of the Wironit extrahard alloy. The most important conclusions are:

- The LCC and HCC alloy structures consist of the $\beta$-Co solution matrix and the $\mathrm{M}_{23} \mathrm{C}_{6}$ carbide precipitates in the interdendritic spaces as well as on the boundaries of crystallites.

- $\alpha$-Co solution was also found for all tested samples.

- Together with the higher content of carbon, the percentage share of carbide precipitates increases and their nature changes from the blocky eutectic (dominating in LCC samples) to blocky dense (dominating in HCC samples).

- With an increase in carbon content, the $T_{\text {liq }}$ temperature decreases and $T_{\text {sol }}$ increases.

\section{Compliance with Ethical Standards}

Conflict of interest The authors declare that they have no conflict of interest.

\section{Open Access}

This article is distributed under the terms of the Creative Commons Attribution 4.0 International License (http:// creativecommons.org/licenses/by/4.0/), which permits unrestricted use, distribution, and reproduction in any medium, provided you give appropriate credit to the original author(s) and the source, provide a link to the Creative Commons license, and indicate if changes were made.

\section{REFERENCES}

1. M. Walczak, K. Beer, B. Surowska, J. Borowicz, The issue of using remelted CoCrMo alloys in dental prosthetics. Arch. Civ. Mech. Eng. 12(2), 171-177 (2012)

2. P. Ravindran, K. Manisekar, R. Narayanasamy, P. Narayanasamy, Tribological behaviour of powder metallurgy-processed aluminium hybrid composites with the addition of graphite solid lubricant. Ceram. Int. 39(2), 1169-1182 (2013)

3. P. Ravindran, K. Manisekar, P. Radhika, P. Narayanasamy, Tribological properties of powder metallurgy_processed aluminium self-lubricating hybrid composites with SiC additions. Mater. Des. 45(3), 561-570 (2013)

4. G. Pitchayyapillai, P. Seenikannan, P. Balasundar, P. Narayanasamy, Effect of nano silver on microstructure, mechanical and tribological properties of cast aluminum 6061 alloy. Trans. Nonferr. Met. Soc. China 27(10), 2137-2145 (2017)

5. K.M. Sree Manu, V.G. Resmi, M. Brahmakumar, P. Narayanasamy, T.P.D. Rajan, C. Pavithran, B.C. Pai, Squeeze infiltration processing of functionally graded aluminum-SiC metal ceramic composites. Trans. Indian Inst. Met. 65(6), 747-751 (2012)

6. S. Ramanathan, B. Vinod, P. Narayanasamy, M. Anandajothi, Dry sliding wear mechanism maps of Al-7Si-0.3 Mg hybrid composite: novel approach of agro-industrial waste particles to reduce cost of material. J. Bio Tribo Corros. 5(2), 32 (2019)

7. K. Beer-Lech, B. Surowska, Research on resistance to corrosive wear of dental CoCrMo alloy containing post-production scrap. Eksploatacja i Niezawodnosc Maintenance and Reliability 17(1), 90-94 (2015)

8. ISO 22674:2016 Dentistry-metallic materials for fixed and removable restorations and appliances

9. S. Mineta, S. Namba, T. Yoneda, K. Ueda, T. Narushima, Carbide formation and dissolution in biomedical Co-Cr-Mo alloys with different carbon contents during solution treatment. Mater. Trans. A Phys. Metall. Mater. Sci. 41, 2129-2138 (2010)

10. J.V. Giacchi, C.N. Morando, O. Fornaro, H.A. Palacio, Microstructural characterization of as-cast biocompatible Co-Cr-Mo alloys. Mater. Charact. 62, 53-61 (2011)

11. L.E. Ramirez-Vidaurri, M. Castro Román, M. Herrera Trejo, C.V. García, J. López, E. Almanza Casaset, Cooling rate and carbon content effect on the fraction of secondary phase precipitate in as cast microstructure of ASTM F75 alloy. J. Mater. Process. Technol. 209, 1681-1687 (2009)

12. J.V. Giacchi, O. Fornaro, H.A. Palacio, Microstructural evolution during solution treatment of $\mathrm{Co}-\mathrm{Cr}-$ Mo-C biocompatible alloys. Mater. Charact. 68, 49-57 (2012)

13. R. Rosenthal, B.R. Cardoso, I.S. BottR, P.R. Paranhos, E.A. Carvalh, Phase characterization in as-cast F-75 Co-Cr-Mo-C alloy. J. Mater. Sci. 45(15), 4021-4028 (2010) 
14. T. Narushima, S. Mineta, Y. KuriharaK, Ueda, precipitates in biomedical $\mathrm{Co}-\mathrm{Cr}$ alloys. J. Miner. Met. Mater. Soc. 65(4), 489-504 (2013)

15. H. Mancha, E. Carranza, J.I. Escalante, G. Mendoza, M. Mendez, F. CepedaE, Valdes, M23C6 carbide dissolution mechanisms during heat treatment of ASTM F-75 implant alloys. Mater. Trans. A Phys. Metall. Mater. Sci. 32, 979-984 (2001)

16. M. Herrera, A. Espinoza, J. Méndez, M. Castro, J. López, J. Rendón, Effect of C content on the mechanical properties of solution treated as-cast ASTM F75 alloys. J. Mater. Sci. 16, 607-611 (2005)

17. M. Mori, K. Yamanaka, H. Matsumoto, A. Chiba, Evolution of cold-rolled microstructures of biomedical $\mathrm{Co}-\mathrm{Cr}-\mathrm{Mo}$ alloys with and without $\mathrm{N}$ doping. Mater. Sci. Eng. A 528, 614-621 (2010)

18. S. Cai, M. Daymond, Y. Ren, Stress induced martensite transformation in $\mathrm{Co}-28 \mathrm{Cr}-6 \mathrm{Mo}$ alloy during room temperature deformation. Mater. Sci. Eng. A 580, 209-216 (2013)

19. M.U. Farooq, U. Klement, G. Nolzeet, The role of $\alpha$ to epsilon-Co phase transformation on strain hardening of a Co-Cr-Mo laser clad. Mater. Sci. Eng. A 445-446, 40-47 (2007)

20. C.B. Song, H.B. Park, H.G. Seong, H.F. López, Development of athermal $\varepsilon$-martensite in atomized Co-Cr-Mo-C implant alloy powders. Acta Biomater. 2, 685-691 (2006)

21. K. Beer, K. Pałka, B. Surowska, M. Walczak, A quality assessment of casting dental prosthesis elements. Eksploatacja i Niezawodnosc - Maintenance and Reliability 15(3), 230-236 (2013)

22. M. Szala, K. Beer-Lech, K. Garncarczyk, O.B. Kilic, P. Pędrak, A. Ozer, A. Skic, Microstructural characterization of Co-Cr-Mo casting dental alloys. Adv. Sci. Technol. Res. J. 11(4), 76-82 (2017)

23. M. Gomez, H. Mancha, A. Salinas, J.L. Rodríguez, J. Escobedo, M. Castro, M. Méndez, Relationship between microstructure and ductility of investment cast ASTM F-75 implant alloy. J. Biomed. Mater. Res. 34(2), 157-163 (1997)

24. C. Montero-Ocampo, M. Talavera, H. Lopez, Effect of alloy preheating on the mechanical properties of AsCast Co-Cr-Mo-C alloys. Metall. Mater. Trans. A Phys. Metall. Mater. Sci. 30, 611-620 (1999)

25. K. Asgar, F.A. Peyton, Effect of casting conditions on some mechanical properties of cobalt-base alloys. J. Dent. Res. 40, 73-86 (1961)

26. W.V. Youdelis, O. Kwon, Carbide phases in cobalt base superalloy: role of nucleation entropy in refinement. Met. Sci. 17(8), 379-381 (1983)

27. B. Henriques, D. Soares, F.S. Silva, Microstructure, hardness, corrosion resistance and porcelain shear bond strength comparison between cast and hot pressed Co-Cr-Mo alloy for metal-ceramic dental restorations. J. Mech. Behav. Biomed. Mater. 12, 83-92 (2012)

28. S. Zangeneh, H.R. Lashgari, A. Roshani, Microstructure and tribological characteristics of aged $\mathrm{Co}-28 \mathrm{Cr}-$ 5Mo-0.3 C alloy. Mater. Des. 37, 292-303 (2012)

29. C. Balagna, S. Spriano, M.G. Faga, Characterization of Co-Cr-Mo alloys after a thermal treatment for high wear resistance. Mater. Sci. Eng. C Mater. Biol. Appl. 32, 1868-1877 (2012)

30. R. Kaiser, K. Williamson, C. O'Brien, S. RamirezGarcia, D. Browne, The influence of cooling conditions on grain size, secondary phase precipitates and mechanical properties of biomedical alloy specimens produced by investment casting. J. Mech. Behav. Biomed. Mater. 24, 53-63 (2013)

31. K. Yamanaka, M. Mori, A. Chiba, Effect of nitrogen on the microstructure and mechanical properties of Co-33Cr-9 W alloys prepared by dental casting. J. Mech. Behav. Biomed. Mater. 50, 268-276 (2015)

32. L. Reimann, L.A. Dobrzański, Influence of the casting temperature on dental Co-base alloys properties. Arch. Mater. Sci. Eng. 60(1), 5-12 (2013)

33. www.bego.com. Accessed 12 Nov 2018

34. F. Binczyk, J. Śleziona, T. Mikuszewski, Effect of repeated remelting on the chemical composition and structure of nickel alloys. Arch. Foundry Eng. 10(1), 189-194 (2010)

35. F. Binczyk, J. Śleziona, The ATD thermal analysis of selected nickel superalloys. Arch. Foundry Eng. 10(2), 13-19 (2010)

36. F. Binczyk, Solidification Process, "Microstructure, Density and Hardness of the Mg-Al Alloys with Zn, $\mathrm{Cu}$, Ni and AlTiB Additions", Solid State Phenomena, Light Metals and their Alloys I-Technology, Microstructure and Properties (Trans Tech Publications Ltd., Switzerland, 2011), pp. 91-99

37. F. Wever, H. Lange, Mitt. Kais,-Wilh.-Inst. Eisenforschg. 11, 293-308 (1929)

38. S. Mineta, A.S. Namba, T. Yoneda, K. Ueda, T. Narushima, Precipitates in biomedical $\mathrm{Co}-28 \mathrm{Cr}-$ $6 \mathrm{Mo}-(0-0.41) \mathrm{C}$ alloys heat-treated at $1473 \mathrm{~K}$ to $1623 \mathrm{~K}\left(1200^{\circ} \mathrm{C}\right.$ to $\left.1350^{\circ} \mathrm{C}\right)$. Metall. Mater. Trans. A Phys. Metall. Mater. Sci. 43, 3351-3358 (2012)

39. K.M. Mantrala, M. Das, V.K. Balla, ChS Rao, V.V.S.K. Rao, Additive manufacturing of $\mathrm{Co}-\mathrm{Cr}-\mathrm{Mo}$ alloy: influence of heat treatment on microstructure, tribological, and electrochemical properties. Front. Mech. Eng. 1, 1-7 (2015)

Publisher's Note Springer Nature remains neutral with regard to jurisdictional claims in published maps and institutional affiliations. 